\section{Viviane Mendes}

Jornalista; especialista em Comunicação Televisiva; mestranda do Programa de Mestrado em Comunicação da Universidade Municipal de São Caetano do Sul - USCS; bolsista da Coordenação de Aperfeiçoamento de Pessoal de Nível Superior Capes.

"A televisão já faz parte do cotidiano da sociedade globalizada, de forma que nenhum grupo social possa ignorála por muito tempo. Assim, os constantes argumentos de que esse meio apenas produz e gera hábitos maléficos não têm mais validade". (2011: 25). Foi com essa perspectiva que Carlos Barros Monteiro apresentou o livro Para que serve a TV legislativa no Brasil e no mundo', lançado em junho de 2011, em São Paulo, pela Editora Biografia.

Jornalista, radialista, professor universitário e também palestrante, Monteiro reuniu em seu livro releituras do cenário político brasileiro, bem como informações acerca do processo de criação e implantação de um canal legislativo. Com prefácio de Cecília Peruzzo (docente do Programa de PósGraduação em Comunicação Social da Universidade Metodista de São Paulo - Umesp), o livro é o primeiro dedicado integralmente ao assunto publicado no País. De uma forma didática e esclarecedora, a obra apresenta as estruturas técnicas e operacionais de uma TV pública, a construção da grade de programação e, principalmente, a força desses canais públicos como veículos de disseminação da cultura, educação, prestação de serviços e formação cidadã.

Monteiro é mestre em Comunicação Social, pela Umesp, mesma instituição na qual cursa Doutorado em Comunicação e TV Digital. Atualmente, coordena o curso de Comunicação Social (Publicidade e Propaganda; Relações Públicas; Jornalismo; Rádio, TV e Internet) da Universidade Cruzeiro do Sul, é professor assistente na Faculdade do Povo FAP, ambas na capital paulista, e também na USCS - Universidade Municipal de São Caetano do Sul. Sempre autêntico, o jornalista não hesita em declarar que seus alunos são seu incentivo de aprendizado diário. Prova desse companheirismo está impressa na dedicatória especial que Monteiro fez a eles em seu livro.

Com um título sugestivo, Para que serve a TV legislativa no Brasil e no mundo, o jornalista incita o leitor a conhecer as finalidades desse meio, tendo em vista que, segundo ele, muitas pessoas ainda desconhecem este tipo de modalidade de TV.

O livro, de 226 páginas, é resultado de 16 anos de pesquisas em telejornalismo com ênfase em TVs públicas e

\footnotetext{
${ }^{1}$ Monteiro, Carlos Barros. Para que serve a TV legislativa no Brasil e no mundo. São Paulo: Biografia, 2011. 226p.
}

\section{Cidadania na TV, transparência nas informações ou marketing político? Citizenship on TV, information transparency and political marketing?}

legislativas, inicialmente apresentado como dissertação de mestrado, intitulado "TV Câmara de Bauru: papel social do canal legislativo e suas relações com a comunidade local". Vale destacar que o jornalista foi um dos responsáveis pelo projeto de implantação da TV Câmara de Bauru, em São Paulo, inaugura-

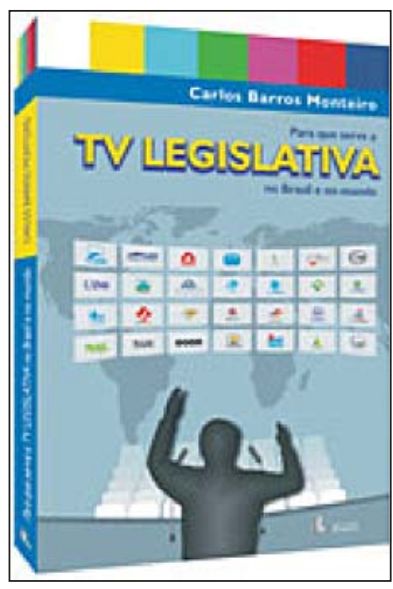
do em 1ำ de agosto de 1998, data do aniversário de 102 anos da cidade, sendo este "[...] um dos primeiros canais de televisão legislativa do Brasil a funcionar com 24 horas de programação diária ainda que com programas não próprios" (2011: 143).

Na obra sob foco, o que mais chama a atenção - além da linguagem, que é de fácil compreensão - é a criatividade do autor em nomear os tradicionais capítulos em "vinhetas" (em televisão, trata-se de uma representação audiovisual que marca a abertura, o intervalo ou o encerramento de um determinado programa; em rádio, a vinheta tem a mesma finalidade, porém é apresentada em áudio; em se tratando de um livro, são as páginas que marcam a transição de um capítulo para outro). Ilustrando cada página dos capítulos, observa-se o desenho de uma pequena claquete contendo o título do livro, o nome do autor, a editora e a data de publicação. Algo muito original e que, até então, não tinha sido visto em nenhum outro trabalho do gênero.

Como não poderia deixar de ser, Monteiro trouxe para as páginas do livro seus quase 25 anos de experiência em televisão, vividos em algumas das principais emissoras de TV do País, como TV Timon (SBT), TV Antena 10 (extinta Rede Manchete), Rede Globo Oeste Paulista (TV Globo), TV São Paulo Centro (Band) e TV Unicsul (Canal Universitário de São Paulo), dentre outras, além de produtoras e agências de publicidade, por exemplo.

Apropriando-se dos termos "vinheta de abertura", "vinheta de passagem" e "vinheta de encerramento", Monteiro envolve o leitor na temática, possibilitando-Ihe ter uma visão mais crítica sobre o papel desse meio de comunicação, que tem por finalidade servir a sociedade. As "vinhetas" constituem, portanto, um convite do autor para que o leitor venha a compreender para que servem as TVs legislativas. Outros termos comumente utilizados na televisão e no rádio, e que o 


\section{Cidadania na TV, transparência nas informações ou marketing político?}

autor apresentou em sua obra, são "Sobe créditos", que, no livro, apresenta a conclusão do autor sobre o tema, e "Um oferecimento...", anexo contendo glossário político. Acredita-se que todos esses recursos tenham sido uma estratégia do autor para tornar a leitura mais aprazível.

É preciso enfatizar que Para que serve a TV legislativa no Brasil e no mundo não se caracteriza como uma literatura político-partidária. Não há indícios, na obra, que mostrem o interesse do autor em formar opinião dos leitores a respeito da política do País; pelo contrário, existe um empenho exacerbado em mostrar a importância desses canais como veículos capazes de formar cidadãos conscientes. No livro, Monteiro defendeu as peculiaridades das TVs legislativas que, segundo ele, mostram muitas coisas, inclusive política, porém não estão vinculadas a nenhum governo ou partido político. A programação é multicultural e, segundo o próprio autor, tem a essência das TVs educativas de fato.

Abre-se aqui um parêntese para uma observação. Iniciando a leitura, em vinheta de abertura (primeiro capítulo do livro), Monteiro fez uma breve introdução ao assunto proposto em seu livro e, nas linhas finais, declarou: "A participação da sociedade pode ser ampliada com mais programas e de forma mais direta, inclusive com sugestão de pautas ou até como integrante de um eventual Conselho Gestor" (2011: 20) - e o texto é finalizado em mais quatro linhas. De certa forma, cria-se uma expectativa de que a obra irá apontar quais os caminhos para essa participação mais ativa da sociedade; no entanto, o livro traça muito mais um panorama das TVs públicas, tanto no Brasil quanto no mundo. Por outro lado, o rico teor de informações que o jornalista apresentou, sem dúvida alguma, torna a obra inédita, pois até então não se tinha conhecimento, em livro, sobre a infraestrutura das TVs legislativas no Brasil e, até mesmo, no mundo da maneira como foi delineada por Monteiro, ou seja, com riqueza de detalhes.

Contudo, por mais que o autor tenha declarado que as TVs legislativas apresentam uma programação multicultural, Monteiro não relatou de forma mais aprofundada sobre os demais conteúdos apresentados por esses canais. "O canal mineiro tem uma programação bastante eclética (...)" e "A programação da TV Assembleia de São Paulo é diversificada" (2011: 126) são apenas sínteses superficiais que dão a entender que a programação desses canais, de fato, não é pautada apenas por conteúdos políticos, causando com isso um discurso ambíguo. Afinal, em outros momentos, o jornalista foi taxativo e, em diversas páginas do livro, endossou que a grade de programação desses canais é composta, boa parte, por transmissões ao vivo das sessões legislativas, reuniões de comissões, sessões solenes, programas de debates, principalmente com políticos, personalidades e, até mesmo, com a comunidade.
Observam-se momentos na obra em que o jornalista trouxe à baila recortes do cenário político brasileiro que pode causar interpretações equivocadas por parte do leitor. Em alguns desses recortes, a impressão que se tem é de que esses canais são utilizados apenas como forma de ataque entre membros do governo, conforme se pode ver na declaração do ex-ministro do Superior Tribunal Federal Eros Grau, que Monteiro destacou: "Grau afirmou, em entrevista, que as transmissões ao vivo das sessões de julgamentos do STF pela TV só vão ser revistas quando maluco se sentir prejudicado e agredir ou der um tiro num ministro" (2011: 119).

No primeiro capítulo, intitulado "Vinheta de abertura", Monteiro relatou, em 37 páginas, o surgimento desses canais legislativos no Brasil e no mundo, seus modelos e sistemas de transmissões, além de ter colocado em pauta temas como a diferença entre emissora, canal e rede de televisão, bem como o cenário das televisões públicas educativas.

Em "Vinheta de passagem", o jornalista iniciou o segundo capítulo apresentando a Lei n. 8.977, de 6 de janeiro de 1995, que diz respeito à Lei do Cabo. Nas páginas seguintes, o autor traçou um panorama das TVs legislativas no mundo e no Brasil, assim como a criação das TVs Senado, Câmera Federal, Justiça, Assembleias Legislativas e Câmaras Municipais.

Neste capítulo, o que chama a atenção é a releitura de casos, como a antológica troca de farpas entre os senadores Antônio Carlos Magalhães, da Bahia, e Jáder Barbalho, do Pará, ocorrida em 21 de março de 2001, no item "Escândalo via satélite", que vale a pena ser descrito:

[...] Na tarde daquele dia, Jáder usou a tribuna do Senado e reclamou que estava sendo alvo de uma agressiva campanha de ACM. Durante sua fala, o senador do Pará disse que "existem algumas figuras que acreditam que esse país não tem memória. É a velha prostituta pregando castidade". ACM não deixou por menos. Instantes depois, o baiano retrucou com ironia: "Todo mundo sabe que não sou prostituta. Eu não seria nem se quisesse, porque sou muito masculino. Mas todo mundo sabe que ele (Jáder) é ladrão". Briga de caciques: ACM, figura peso-pesado do PFL, rebatizado de Democratas em 2008 (partido conservador e que se assume de direita) e Jáder, um general do PMDB (partido que recebe muitas críticas de fisiologista porque sempre tem apoiado todos os presidentes desde a redemocratização do país, independente da ideologia de quem esteja no poder) que fora eleito presidente do Senado, sucedendo o desafeto baiano [...] (2011: 97).

Outro fato antológico lembrado pelo autor, neste capítulo, foi a denúncia de violação do painel eletrônico de votação do plenário do Senado Federal, episódio em que ACM era 
suspeito de negligência quando presidia o Senado entre 1999 e 2001.

Fechando o livro, em "Vinheta de encerramento", Monteiro discutiu a democratização da informação, a publicidade sustentável e o que é o canal da cidadania. No item "Sobe créditos", que trata das conclusões, o autor destacou: "A lei que criou os Canais Básicos de Utilização Gratuita deve ser exercitada para democratizar não apenas o acesso, mas também a participação democrática da população" (2011: 170-171), frase que permite ao leitor um leque de interpretações, principalmente no que tange às informações sobre as possibilidades de a população ter uma participação ativa e democrática dentro desses canais.

Confessa-se que a percepção em relação às TVs públicas mudou após o conhecimento, por meio do livro, do que esses canais transmitem diariamente e, principalmente, da estrutura dessas emissoras. É visível que, a partir da década de 1990, surgiu uma nova vertente da comunicação governamental no Brasil com a criação das TVs legislativas. Conforme afirmou Monteiro, "É pouco provável que algum cidadão conhecedor desses canais ainda se posicione contra sua existência" (2011: 95). Afinal, por mais que a criação
Cidadania na TV, transparência nas informações ou marketing político? de tais emissoras tenha surgido para democratizar o acesso da população a informações acerca da vida política e social do País, há de se compreender que, na medida em que o elemento "televisão", quando utilizado como estratégia de comunicação por um poder público, pode ser positivo, é possível estimular a participação política do cidadão, especialmente no exercício da cidadania.

É perceptível que a criação desses canais colabora positivamente para a transparência das informações tratadas pelos poderes públicos. Todavia, espera-se que este processo de transparência permita a interação social e, de certa forma, possa contribuir para ampliar a esfera pública e, por que não dizer, consolidar a ideia de que é possível aprimorar o processo democrático do País.

A obra Para que serve a TV legislativa no Brasil e no mundo, de Carlos Barros Monteiro, de fato preenche uma lacuna e torna-se imprescindível aos profissionais da comunicação, a pesquisadores, professores, alunos e à própria sociedade como um todo. Cabe aos interessados ler a obra e formar sua opinião a respeito do tema apresentado pelo jornalista, para só então tirarem suas próprias conclusões. 